\title{
Defesa do status fitossanitário de Área Livre de Moko da Bananeira em Santa Catarina
}

\author{
Fabiane Dos Santos' 1 Geovane Pedro De Souzaㄹ, Fabiana Alexandre Branco ${ }^{2}$, Alexandre Mees ${ }^{3}$, Ricardo Miotto Ternus ${ }^{4}$, \\ Janice Ebel ${ }^{5}$, Júlio Vilperte ${ }^{6}$, Clóvis Adriano Teixeira Paes ${ }^{7}$ e Agnaldo Trevisol dos Santos ${ }^{8}$
}

\begin{abstract}
Resumo - A bactéria Ralstonia solanacearum raça 2, agente causal do Moko da Bananeira, é uma praga quarentenária presente em alguns estados do norte e do nordeste brasileiros, porém Santa Catarina possui a condição de Área Livre da Praga (ALP). O presente informativo técnico descreve as ações de erradicação e delimitação de um foco da doença ocorrido no município de Antônio Carlos, SC, região da grande Florianópolis, no ano de 2018. A ação assegurou a manutenção da Área Livre do Moko da Bananeira em Santa Catarina com a eliminação de todas as plantas sintomáticas e adjacentes localizadas na área perifocal e inspeções em bananeiras e helicônias num raio de cinco quilômetros.
\end{abstract}

Termos para indexação: Erradicação; Ralstonia solanacearum raça 2; praga quarentenária.

\section{Protection of the phytosanitary status of Pest Free Area - Moko Disease of Banana in Santa Catarina}

Abstract - The bacterium Ralstonia solanacearum race 2, the causing agent of Moko Disease of Banana is a quarantine pest present in some northern and northeastern Brazilian states, but Santa Catarina has the status Pest Free Area (PFA). This technical paper describes the actions of eradication and delimitation of a disease outbreak, which occurred in the city of Antônio Carlos, SC, in 2018. The action ensured the condition of Moko Disease of Banana in Santa Catarina, with the elimination of all symptomatic plants and nearest focus and inspections within a radius of five kilometers, in banana plants and heliconias.

Index Terms: Eradication; Ralstonia solanacearum race 2; quarantine pest.

\section{Doenças de importância quarentenária no estado de Santa Catarina}

O estado de Santa Catarina destacase como o terceiro maior produtor nacional de banana (Musa spp.), com cerca de 30 mil hectares dos quase 500 mil plantados no Brasil, responsável pela renda de vários agricultores catarinenses (EPAGRI, 2019).

Um dos fatores limitantes para a produção de banana é a incidência de pragas e doenças, agravada pela baixa diversidade genética e consequentemente pela alta suscetibilidade dos cultivares aos diferentes organismos noci- vos (WARMAN \& AITKEN, 2018). Dentre as doenças que ameaçam a produção de banana, algumas são consideradas quarentenárias, ou seja, aquelas com importância econômica potencial que podem estar presentes ou ausentes numa determinada região. Quando presentes, tais doenças não estão amplamente distribuídas e se encontram sob controle oficial (IPPC, 2019). As principais doenças quarentenárias ausentes para o Brasil são o vírus Banana bunchy top vírus (BBTV) e o fungo Fusarium oxysporum f.sp. cubense, raça 4 tropical (FocR4T) (BRASIL, 2018). As doenças quarentenárias presentes no Brasil, sob constante fiscalização da Companhia Integrada de Desenvolvimento Agrícola de Santa
Catarina (Cidasc) e sujeitas a restrições fitossanitárias, são a Pseudocercospora fijiensis (Sigatoka-negra) e Ralstonia solanacearum raça 2 (Moko da Bananeira) (BRASIL, 2018).

O Moko da Bananeira, causado pela bactéria Ralstonia solanacearum raça 2, está restrito aos estados de Alagoas, Amazonas, Amapá, Pará, Rondônia, Roraima e Sergipe (BRASIL, 2018). O estado de Santa Catarina, entretanto, possui o status fitossanitário de Área Livre da Praga (ALP) (BRASIL, 2013). Devido às características do patógeno e à severidade dos seus danos, não há métodos eficazes de controle químico e cultural para esta doença. Desta forma, adotase o princípio da exclusão, impedindo a»

Recebido em 15/4/2019. Aceito para publicação em 15/8/2019

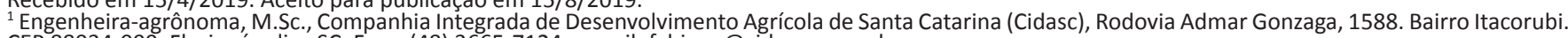
CEP 88034-000. Florianópolis - SC. Fone:(48) 3665-7124, e-mail: fabiane@cidasc.sc.gov.br.

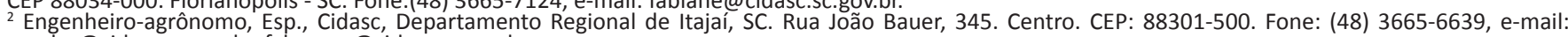
gpedro@cidasc.sc.gov.br, fabranco@cidasc.sc.gov.br.

J Engenheiro agrônomo, Esp., Cidasc. CEP 88034-000. Florianópolis - SC. Fone:(48) 3665-7134, e-mail: amees@cidasc.sc.gov.br.

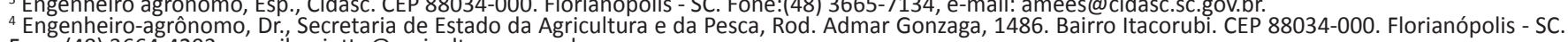

Fone:(48) 3664-4293, e-mail: miotto@agricultura.sc.gov.br.

5 Engenheira agrônoma, Esp., Cidasc, DR de Tubarão, SC. Rua Lauro Muller, 2831. Fone:(48)3631-9606, e-mail: jebel@cidasc.sc.gov.br.

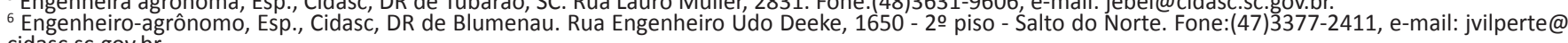
cidasc.sc.gov.br

${ }_{7}$ Engenheiro-agrônomo, Esp., Cidasc, DR de Criciúma. Rua General Lauro Sodré, 200. Fone:(48)3529-0335, e-mail: clovispaes@cidasc.sc.gov.br

8 Técnico Agrícola, Cidasc, DR de Criciúma. Rua General Lauro Sodré, 200. Fone:(48) 3529.0239, e-mail: atsantos@cidasc.sc.gov.br 
entrada do patógeno na área de cultivo e o princípio da erradicação com a eliminação imediata das plantas, caso os sintomas da doença sejam detectados (BLOMME et al., 2017).

\section{Ações de fiscalização}

A condição fitossanitária de ALP para Moko da Bananeira deve ser assegurada mediante levantamentos oficiais de detecção realizados semestralmente pela Cidasc em bananais comerciais ou domésticos localizados tanto na zona rural quanto na urbana, bem como em viveiros produtores de mudas de banana e helicônias. Havendo laudo oficial que confirme a presença da bactéria é estabelecido prazo inferior a 60 dias para eliminação de todas as plantas sintomáticas e adjacentes, impedindo o replantio no prazo de 12 meses, além da interdição e a proibição do trânsito de qualquer parte de bananeiras e helicônias na propriedade. As inspeções fitossanitárias são intensificadas num raio de cinco quilômetros a partir do foco da doença (BRASIL, 2009).

\section{Ações para habilitação de responsáveis técnicos}

A ALP é atestada pelo sistema de certificação fitossanitária que envolve a emissão de Certificados Fitossanitários de Origem (CFO) e Certificados Fitossanitários de Origem Consolidado (CFOC), por responsáveis técnicos habilitados em cursos específicos, organizados pela Cidasc e aprovado pelo Mapa. O curso aborda regras de certificação fitossanitária, permissão de trânsito de vegetais (PTV), noções sobre normas internacionais, além de aspectos sobre classificação taxonômica, levantamento e mapeamento em condições de campo, identificação, coleta, acondicionamento e transporte da amostra, bioecologia, sintomas, sinais, plantas hospedeiras, ações de prevenção e métodos de controle (BRASIL, 2016). Assim, os responsáveis técnicos e a Cidasc trabalham conjuntamente para que eventuais suspeitas do patógeno possam ser rapidamente saneadas.
As comunicações sobre suspeitas podem vir de meios externos a vigilância ativa, como de outros profissionais e até mesmo dos produtores. Da interação entre técnicos da Epagri e Cidasc, foi constatada a presença de plantas infectadas por $R$. solanacearum, raça 2 , em um bananal comercial dos cultivares prata e branca, localizado no município de Antônio Carlos, SC, em fevereiro de 2018. A presença da doença foi confirmada por laudo laboratorial, baseado em análises de sintomatologia, sinais, morfologia e teste de hipersensibilidade, emitido em 4 de abril de 2018 pelo centro de diagnóstico "Marcos Enrietti", credenciado pelo Mapa para diagnose fitossanitária.

\section{Denúncias}

\section{Inquérito fitossanitário}

A Cidasc realizou um inquérito fitossanitário com o objetivo de reconhecer a área e averiguar informações sobre a propriedade onde estava localizado o foco, tais como: Nome do proprietário, variedades e origem das mudas, tratamentos fitossanitários efetuados, além da época de início do aparecimento de sintomas. Produtores vizinhos também foram questionados quanto à observância de possível presença de plantas sintomáticas em suas áreas de produção, bem como a origem do material propagativo. Concomitantemente a área perifocal foi avaliada por imagens aéreas obtidas por Veículo Aéreo Não Tripulado (VANT) com auxílio da 1a Companhia do Batalhão da Polícia Militar Ambiental de Santa Catarina (Figura 1 A).

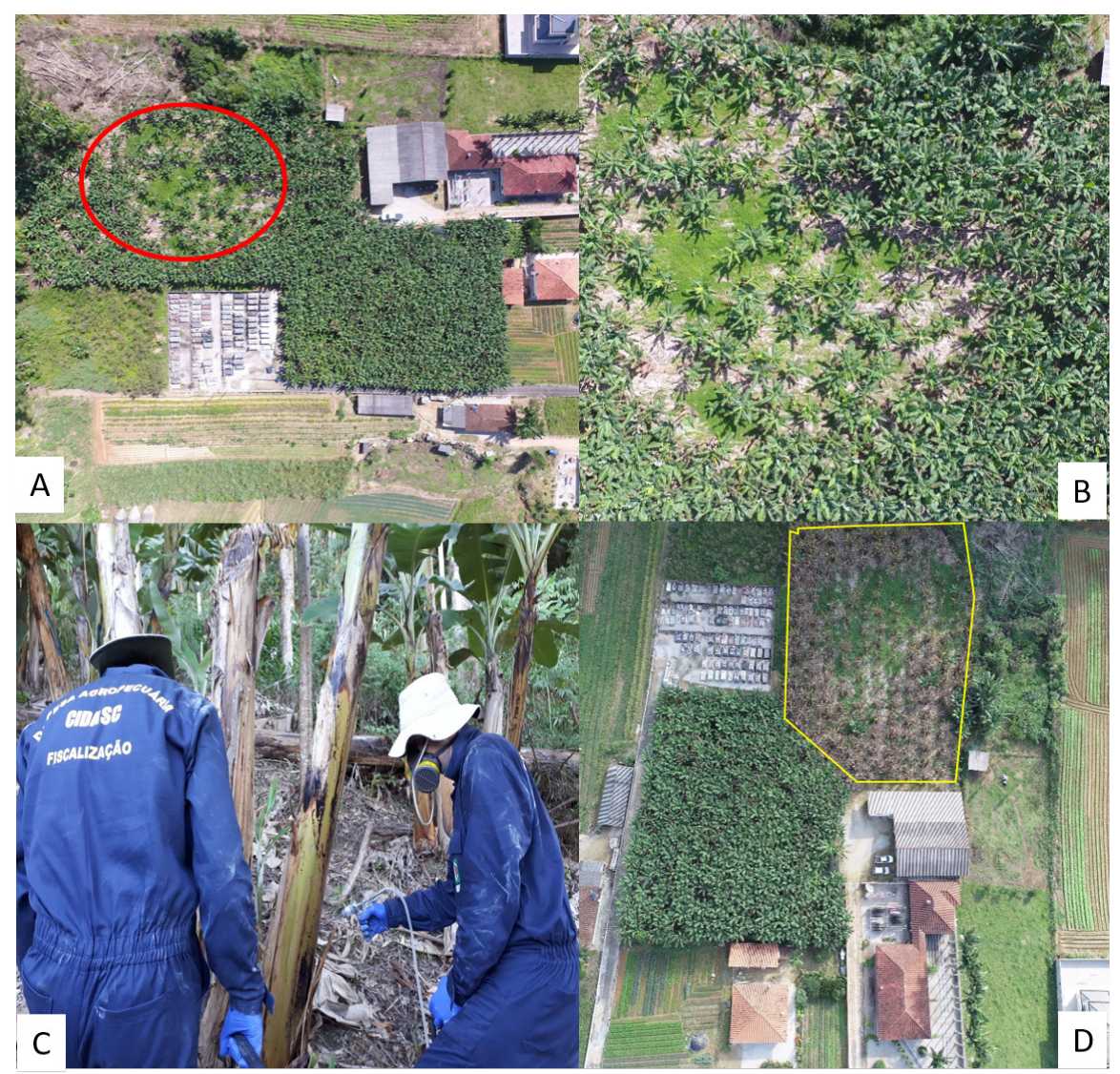

Figura 1. (A) Detalhe do foco do Moko da Bananeira na Unidade de Produção; (B) Reboleira denotando o corte de plantas doentes na área foco; (C) Injeção de herbicida no pseudocaule de bananeiras; (D) Área perifocal após a erradicação. Fotos: Peterson Marcos Lima (A, B). Fabiana Alexandre Branco (C); Diego Hemkemeier Silva (D)

Figure 1. (A) Detail of Moko disease focus in banana crops area; (B) Site denoting the cutting of diseased plants in the focus area; $(C)$ Injection of herbicide into banana pseudostem; (D) Perifocal area after eradication. Photos: Peterson Marcos Lima $(A, B)$. Fabiana Alexandre Branco (C); Diego Hemkemeier Silva (D) 
Um dos principais meios de disseminação do Moko da Bananeira é o material propagativo de bananas e helicônias. O mesmo sucede com outras doenças, a exemplo do que ocorreu em Tupi Paulista, SP, onde foram destruídas 4.700 plantas de videira com a presença da bactéria quarentenária Xanthomonas campestris pv. viticola (RODRIGUES NETO et al., 2011). Foi evidenciada pela Cidasc a aquisição de mudas de rizomas de origem não identificada, o que é proibido e constitui infração de natureza grave (SANTA CATARINA, 2010).

\section{Ações para sanar o problema}

A propriedade foi interditada e todas as plantas presentes na área perifocal de $20 \mathrm{~m}$, determinada a partir da borda da reboleira onde foi encontrada a planta foco, foram erradicadas (Figura 1 B). A erradicação das plantas na área perifocal foi feita por meio de injeção contendo herbicida com princípio ativo glifosato (concentração de $48 \%$ ). A solução foi preparada na proporção de $50 \%$ de herbicida e $50 \%$ de água, sendo aplicada em posições diferentes do pseudocaule até que fosse atingida a dose de $50 \mathrm{ml}$ da solução por planta. O herbicida foi injetado com a agulha inclinada, permanecendo no interior da planta por alguns segundos para evitar o regurgitamento do líquido (Figura $1 \mathrm{C}$ ). Foram erradicadas aproximadamente 300 touceiras em uma área de 0,34 hectares (Figura $1 \mathrm{D}$ ), respeitando-se o raio de $20 \mathrm{~m}$ da área perifocal, com base na IN 17/2009, a qual determina que a área abrangida deve ser de $10 \mathrm{~m}$, a partir do foco, podendo ser ampliada até o máximo de $20 \mathrm{~m}$, ou reduzida até o mínimo de cinco metros. A área remanescente de 0,26 hectares foi liberada para o manejo e colheita, devendo haver a desinfestação das ferramentas utilizadas. $O$ produtor foi informado da necessidade de eliminação de possíveis expensas e rebrotes, bem como a necessidade de pousio da área perifocal por um período de doze meses.

A identificação do Moko da Bananeira é facilitada quando há exsudação bacteriana e sintomas nos frutos. Contudo, a coleta de amostras inicialmente é baseada na descoloração vascular do pseudocaule mais intenso no centro e menos aparente na região periférica, antagônico do que ocorre no mal do panamá (BLOMME et al., 2017).

O levantamento de delimitação na área abrangida por um raio de cinco quilômetros a partir do foco de Moko da Bananeira resultou em 210 inspeções (Figura 2), categorizadas em comerciais, domésticas, beira de estrada e rio. Nas inspeções efetuou-se a coleta de nove amostras, resultando em três laudos positivos para a presença de Ralstonia solanacearum, raça 2. Esses três focos encontrados a partir do levantamento de delimitação estavam presentes em locais com poucas bananeiras e, com a erradicação delas, garantiu-se a eliminação do Moko da Bananeira na área de abrangência desse levantamento. A Cidasc realizou a operação de erradicação em 14 dias a partir da emissão do laudo laboratorial, garantindo assim a condição de ALP Moko da Bananeira. O status foi assegurado por inspeções nos meses posteriores, levantamentos fitossanitários realizados semestralmente pela Cidasc e pelo acompanhamento da área por imagens de satélite.

\section{Considerações finais}

- O foco de Moko da Bananeira, foi detectado em região com pouca expressão comercial da bananicultura, distando cerca de 60 quilômetros da região com maior densidade de plantio, facilitando o processo de erradicação.

- A interação entre responsáveis técnicos, extensionistas rurais e profissionais do serviço de defesa sanitária vegetal é fundamental para assegurar a sanidade dos cultivos agrícolas catarinenses.

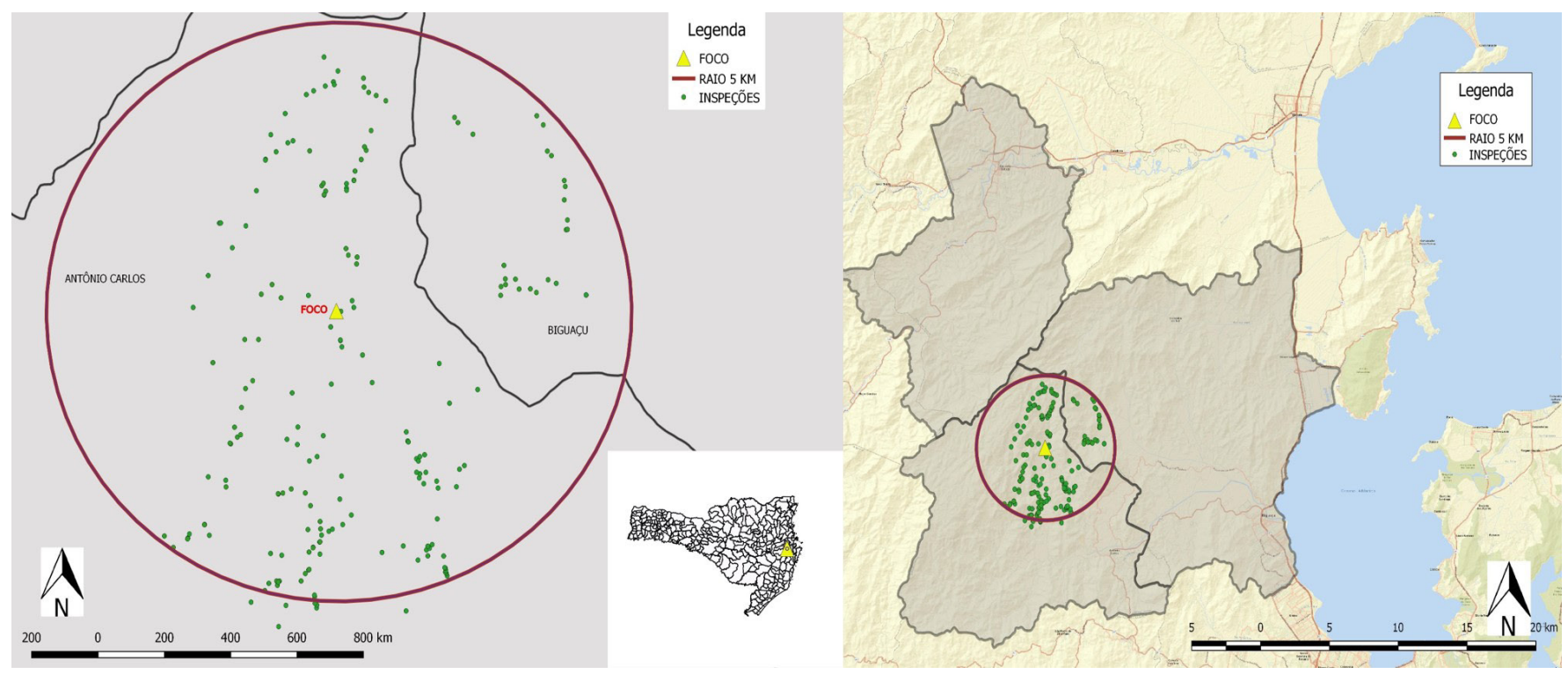

Figura 2. Área de abrangência do raio de cinco quilômetros a partir do foco de Moko da bananeira no levantamento de delimitação. Os pontos verdes correspondem à localização georreferenciada de bananeiras inspecionadas. Autor: Fabiane dos Santos

Figure 2. Radius coverage area of five kilometers from the focus Moko disease on the delimiting survey. The green points correspond to the georeferenced area of inspected banana plants. Author: Fabiane dos Santos 


\section{Agradecimentos}

À Cidasc, em especial, aos colegas que participaram da ação pela dedicação. À Superintendência Federal da Agricultura de Santa Catarina (Mapa/ SFA-SC). Às extensionistas rurais da Epagri de Antônio Carlos, SC. Ao colega Mario Álvaro Aloisio Verissimo pelas contribuições.

\section{Referências}

BRASIL. Ministério da Agricultura, Pecuária e Abastecimento. Instrução Normativa Interministerial nㅇ 38, de 1 de outubro de 2018.

BRASIL. Ministério da Agricultura, Pecuária e Abastecimento. Instrução Normativa Interministerial no 39, de 1 de outubro de 2018.

BRASIL. Ministério da Agricultura, Pecuária e Abastecimento. Instrução Normativa Inter- ministerial no 17, de 27 de maio de 2009 .

BRASIL. Ministério da Agricultura, Pecuária e Abastecimento. Instrução Normativa Interministerial nㅇ 22, de 7 de agosto de 2013 .

BRASIL. Ministério da Agricultura, Pecuária e Abastecimento. Instrução Normativa Interministerial no 33, de 24 de agosto de 2016.

BLOMME, G.; DITA, M.; JACOBSEN, K.S.; VICENTE, L.P.; MOLINA, A.; OCIMATI, W.; POUSSIER, S.; PRIOR, P. Bacterial Diseases of Bananas and Enset: Current State of Knowledge and Integrated Approaches Toward Sustainable Management. Frontiers in Plant Science, v. 8, n. July, p. 1-25, 2017.

EPAGRI. Números da agropecuária catarinense - 2019. Florianópolis, SC, 2019. 65p. (Epagri. Documentos, 291).

IPPC. Glossary of phytosanitary terms. Roma: International Plant Protection Convention, 2019. 40p. Disponível em: https:// www.ippc.int/en/publications/glossaryphytosanitary-terms/. Acesso em: 11 jul. 2019.

RODRIGUES NETO, J.; DESTÉFANO, S.A.L.; RODRIGUES, L.M.R.; PELLOSO, D.S.; OLIVEIRA JÚNIOR, L.C. Grapevine bacterial canker in the State of São Paulo, Brazil: detection and eradication. Tropical Plant Pathology, $\mathrm{v}$. 36, n. 1, p. 42-44, 2011.

SANTA CATARINA. Decreto Estadual no 3.378 de 08, de julho de 2010. Florianópolis, SC: Governo do Estado de Santa Catarina [2016]. Disponível em: http://www.cidasc. sc.gov.br/fiscalizacao/legislacao-2/. Acesso em: 10 de jul. de 2019.

WARMAN, N.M.; AITKEN, E.A.B. The Movement of Fusarium oxysporum f.sp. cubense (Sub-Tropical Race 4) in Susceptible Cultivars of Banana. Frontiers in Plant Science, v.9, n. November, p.1-9, 2018 .
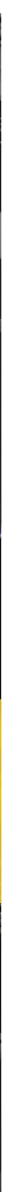